\title{
Modern epizootic situation on avian influenza in the world and Ukraine (development of domestic means of monitoring and diagnostics)
}

\author{
Stegniy B. ${ }^{1}$, Muzyka D. $^{2}$, Pishchanskyi $0 .^{3}$
}

${ }^{1,}{ }^{2}$ NSC «Institute of experimental and clinical veterinary medicine», Pushkinska Str., 83, Kharkiv, 61023, Ukraine, ${ }^{3}$ State research institute of laboratory diagnosis and veterinary-sanitary expertise, Donetska Str. 30, Kyiv, 03151, Ukraine; e-mail: 1admin@vet.kharkov.ua, 22dmuzyka77@gmail.com, ${ }^{3}$ dndildvse@vetlabresearch.gov.ua

The purpose. To analyze modern epizootic situation in the world and Ukraine on highly pathogenic avian influenza, to monitor and develop domestic diagnostics test-system for serological diagnosis of avian influenza at house and wild bird. Methods. Statistical, virologic, immunological, molecular-genetic. Results. Today the majority of countries face the problem of highly pathogenic avian influenza. 30 outbreaks of highly pathogenic avian influenza with different intensity were registered all over the world since 1955. One of the biggest epizootic outbreaks of H5N1 highly pathogenic influenza virus (from 1996 until now) covered almost whole Eurasia, part of Africa and was registered in 63 countries of the world. Now there is difficult epizootic situation concerning viruses of influenza of such subtypes: H5N1, H5N2, H5N5, H5N6, H5N8, and H7N9. Now in Ukraine epizootic situation on highly pathogenic avian influenza is stable and safe. But in 2005-2008 two waves of highly pathogenic avian influenza were registered in Ukraine, which were caused by virus with antigenic formula H5N1. The third wave was been registered in 2016-2017. During all that time scientists of NSC «IECVM» actively participate in diagnosing and anti-epizootic work in close cooperation with State veterinary service of Ukraine. Scientists of NSC «IECVM» in 2005-2008 and 2016-2017 isolated viruses of highly pathogenic avian influenza of subtypes H5N1 and H5N8, studied their biological properties and antigenic characteristics, carried out sequencing and phylogenetic analysis, which allowed determining origin of these viruses and identifying possible ways of pathogen's penetration with wild birds. Conclusions. It is determined that avian influenza and its highly pathogenic alternatives are of real threat for industrial and home poultry and may cause serious economic aftereffects. The first part in system of forestalling this disease is monitoring and duly diagnostics. Therefore development of domestic diagnostic preparations is of utmost importance.

Key words: highly pathogenic avian influenza, epizootic situation, serological diagnostics.

$$
\text { https://doi.org/10.31073/agrovisnyk201811-12 }
$$

Influenza is one of the few infections that pose a serious threat to mankind in the modern world. Its impact on poultry breeding (poultry abolition, imposition of quarantine and other restrictive measures, trade ban, additional veterinary and sanitary measures) leads to significant economic losses both in developed and in developing countries. Influenza occupies a special place as a pathogen which is dangerous to human health and may cause a pandemic with severe consequences. All of the above mentioned factors prompt the international scientific community to carry out constant monitoring and study this disease, namely its epizootology and epidemiology, biological features and genetic structure of this pathogen. Data on the potential of some influenza viruses (especially highly pathogenic) to overcome the interspecific barrier has led to a new wave of environmental studies of the influenza virus, the discovery of both new influenza virus types (influenza D virus in ruminants) [1] and new hosts of the influenza A virus (two new subtypes of hemagglutinin $\mathrm{H} 17, \mathrm{H} 18$ and neuraminidase N10-N11 found in bats in South America) [2]. But the greatest attention in the world is given to influenza A viruses, because especially dangerous highly pathogenic influenza viruses belong to this type.

Influenza A viruses belong to the Orthomyxoviridae family [3, 4]. Wild waterfowl and water-related birds are the main natural reservoir of influenza viruses and play a major role in maintenance of this pathogen's circulation [4]. Influenza viruses of all known subtypes of hemaglutinin ( $\mathrm{H} 1-\mathrm{H} 16)$ and neuraminidase (N1-N9) are isolated from wild birds belonging to more than 100 species of 12 rows. But the largest number of viruses is isolated from the representatives of Anseriformes and Charadriiformes [5, 6, 7, 8]. According to the 
classification of the World Organization for Animal Health, based on the structure of the hemaglutinin restriction site, as well as the ability to cause disease in poultry, influenza viruses are divided into lowpathogenic and highly pathogenic. With regard to low-pathogenic influenza viruses, today their global circulation in the natural reservoir has been proven. Of the huge variety of influenza viruses, highly pathogenic variants of influenza virus, their origin, evolution, pathogenesis in livestock and wild animals and birds [3, 9, 4] attract the greatest interest and attention. Monitoring of pathogens' circulation among poultry and wild birds, as well as early diagnosis are key points in avian influenza's control system, including highly pathogenic. Both for monitoring and for early diagnosis, modern, sensitive, specific diagnostic test systems are required. Taking into account the fact that influenza virus is capable to form rapid mutations and reassortants, it is necessary to carry out constant rotation of antigens in order to replace them with more relevant ones.

Objective. To analyze current epizootic situation in the world and Ukraine regarding highly pathogenic avian influenza, to monitor and develop domestic diagnostic test kits for serological diagnostics of avian influenza in domestic and wild birds.

Material and methods. Current epizootic situation was analyzed according to official data from the State Committee for Procurement of Consumer Goods and the World Organization for Animal Health [10,11,12]. Isolation and accumulation of virus-containing liquid was carried out using chicken embryos (CE) of 9-10 days of age. The serologic identification of isolated isolates was performed using reference sera produced by the Veterinary Laboratories Agency (UK) and the National Scientific Center "Institute of Experimental and Clinical Veterinary Medicine". Inactivation of the virus-containing liquid was carried out in accordance with generally accepted requirements with the use of -propylactone at final concentration of $0.05 \%$. Verification of the inactivation was carried out through three consecutive "blind" passages on CE. The titer of biological activity was calculated using Reed and Mench formula. Inactivated liquid with Montanid ISA 70 VG adjuvant was used in the ratio of 30:70 for immunization of poultry. This mixture was injected into hip muscles in a dose of $0.5 \mathrm{~cm}^{3}[13]$.

Results. After analyzing of epizootic situation regarding to influenza in the world, we have found that most countries of the world are facing the problem of highly pathogenic avian influenza. Since 1955, 30 epizootic ourbreaks of highly pathogenic avian influenza with different intensity have been recorded worldwide. One of the largest epizootics of the highly pathogenic H5N1 influenza virus (from 1996 until nowadays) has covered almost the entire Eurasian continent, part of Africa and was registered in 63 countries of the world [14].

For today, the World Organization for Animal Health has traditionally focused its attention on influenza viruses that are highly pathogenic or might become. Today, circulation and complicated epizootic situation with influenza viruses of the following subtypes are recorded in the world: H5N1, H5N2, H5N5, H5N6, H5N8, H7N9. Since October 2016, highly pathogenic avian influenza has been reported in 55 countries, which recorded 612 active outbreaks among poultry and 506 wild birds. The total number of eliminated poultry is more than 5 million 600 thousand birds.

Analyzing the regional situation with regard to avian influenza, the largest number of affected countries is recorded in Europe (22), which is $41 \%$ of all countries in the region. H5N5, H5N6 H5N8 viruses have been detected in poultry and wild birds in Europe. The number of dead birds (more than 3 million heads) Europe is also the largest. Asia and Oceania are on the second place with $9(25 \%)$ countries which are the most affected. In this region, influenza viruses circulate with the antigenic formulas H5N1, H5N2, H5N6, H5N8, $\mathrm{H} 7 \mathrm{~N} 9$, and the number of destroyed poultry is about 2.5 million.

As for Ukraine, epizootic situation regarding highly pathogenic avian influenza is stable and prosperous for today, but we should not forget that our country has a large natural reservoir of influenza virus - wild birds. Thus, as the result of monitoring studies conducted in 2001-2012 at NSC "IECVM", the circulation of lowpathogenic influenza viruses has been detected among 12 species of Ukrainian avifauna in the Azov-Black Sea region. 69 influenza viruses, which belonged to 15 of the 16 known hemglutinin subtypes and to 7 of the 9 known neuraminidase subtypes, were isolated from the natural reservoir. Totally, 27 antigenic combinations have been isolated, and some of them have been detected for the first time. There is also a large genetic diversity of these viruses, and their connection with other geographic regions (Europe, Southeast Asia, Western Siberia) $[15,16,17]$.

As for highly pathogenic avian influenza, this is not a new infection for Ukraine as well. In 2005-2008, two waves of highly pathogenic avian influenza were registered in our country, which were caused by H5N1 virus. 
The first wave of epizootic outbreak in 2005-2006 infected poultry of household and small industrial poultry farms in the Autonomous Republic of Crimea, Sumy oblast, and Zoo bird in Odessa Zoo. During this period, the disease was registered also in wild birds in Kherson region. The second wave of H5N1 outbreaks was registered in 2008 among domestic and wild birds in the Autonomous Republic of Crimea. Thus, in the period from November 2005 to March 2008, 45 outbreaks of HPAIV were registered in Ukraine among poultry and wild birds. The new, third wave of highly pathogenic avian influenza began in November 2016, when the first cases of avian influenza in Kherson region were recorded. These outbreaks were caused by the new H5N8 influenza virus subtyope. Outbreaks were registered in 2017, namely 9 outbreaks of highly pathogenic H5N8 avian influenza in 4 oblasts (Kherson, Odesa, Chernivtsi, Ternopil, and Mykolayiv) among poultry, wild and zoo birds.

During all three waves of highly pathogenic avian influenza, NSC "IECVM" actively participated in diagnostics and eradicative measures in close cooperation with the State Veterinary Service of Ukraine.

In 2005-2008 and 2016-2017, specialists from NSC "IECVM" isolated H5N1 (strain A / chicken / Sivash / 02/05) and H5N8 (strain A / white-fronted goose / AN / 1-15-12 / 16) highly pathogenic avian influenza virus, studied their biological features and antigenic characteristics, as well as conducted sequencing and phylogenetic analysis, which allowed to determine the origin of these viruses and probable pathways of pathogen's penetration with wild birds. Later, after detailed study, these field isolates became production strains for the development and production of antigens for serological diagnostics. Thus, on the basis of the strain A/chicken/Sivash /02/05 H5N1, which was first isolated and studied in Ukraine, the first domestic diagnostic test kit "AvifluTest H5N1" was developed to detect antibodies against H5N1 influenza virus. According to the results of production tests, the AvifluTest H5N1 test kit is specific, sensitive and registered in Ukraine (RC No. 2743-14-0301-07). This drug was actively used for monitoring research both in the department of avian diseases at NSC "IECVM", as well as in state veterinary laboratories. NSC "IECVM" research team did not stop further research and to broaden the coverage of the influenza virus subtypes, researchers of the Institute developed a test kit for detecting of antibodies against $\mathrm{H} 1-\mathrm{H} 14$ influenza A virus using $\mathrm{HI}$ test (also the first in Ukraine). The national strain of the low-pathogenic influenza A/teal/Dzhankoy/417-11/2010 H5N2 subtype was introduced into this test kit. According to the results of state commission tests, this diagnostic test kit was registered in Ukraine (RC No. VV-00568-06-13). In connection with the emergence of a new H5N8 epizootic strain of influenza virus, which, unlike previously detected strains had another antigenic formula and some biological properties, there was a need to develop and manufacture a new antigen for the delayed hemagglutination reaction. As a result of numerous scientific studies, in co-operation with the State Scientific-Control Institute for Laboratory Diagnosis and Veterinary-Sanitary Expertise, inactivated antigen of of H5N8 highly pathogenic avian influenza virus, strain A / white-fronted goose / AN / 115-12 / 16, was inactivated. The activity of this antigen in hemagglutination test was 1:64-1:128. Immunization of poultry was carried out and specific blood serum was obtained against this virus, which had activity from 5 to $9 \log _{2}$ in $\mathrm{HI}$ test. Also, a technology of influenza A virus antigen purification for the detection of antibodies in ELISA has been developed at NSC "IECVM". 11 methods of influenza A virus purification have been tested, a selection procedure for sensibilization, formulation and response has been carried out. The AvifluTest ELISA test kit specifically reacts with sera containing antibodies to influenza A H1 H16 viruses and does not respond to paramyxoviruses 1-9 serum and serum without antibodies to viral bird diseases. The sensitivity and specificity of the test kit in Iboratories is $100 \%$. This test kit is registered in Ukraine (RC No. VV-00847-06-17).

\section{Conclusions}

Thus, based on the results of the analysis of the current epizootic situation regarding highly pathogenic avian influenza and risks for Ukrainian poultry, it has been found that avian influenza and its high pathogenic variants represent a real threat to industrial and household poultry farming with serious economic consequences in case of penetration of the pathogen. The first link in prevention of this disease is monitoring, rapid diagnostics and, in the context of this, development of domestic diagnostic means, which is a very necessary and urgent task. Today, Ukraine is free from highly pathogenic avian influenza, and sensitive and specific domestic monitoring and diagnostic tools are developed. In the future, in order to maintain sustained epizootic well-being, it is necessary to conduct continuous epidemiological monitoring of the circulation of 
influenza viruses in natural reservoir in order to detect new epizootic and antigenic variants of the influenza virus, which will allow the timely development and introduction of new antigens and test systems for diagnosis.

Bibliography

1. Ferguson L., Olivier A.K., Genova S. et al. (2016). Pathogenesis of Influenza D Virus in Cattle. J. Virol. No 12. 90. P. $5636-5642$.

2. Mehle A. (2014). Unusual influenza A viruses in bats. Viruses. No 9. P. $3438-3449$.

3. Alexander D.J., Capua I. (2009). SpringerLink (Online service) Avian influenza and Newcastle disease a field and laboratory manual. Milan. Springer. $186 \mathrm{p}$.

4. Swayne D.E. (2008). Avian influenza. Ames, lowa. Blackwell. P. 123 - 143.

5. Suss J., Schafer J., Sinnecker H., Webster R.G. (1994). Influenza virus subtypes in aquatic birds of eastern Germany. Arch.Virol. No 1 - 2, 135. P.101 - 114.

6. Hinshaw V.S., Air G.M., Gibbs A.J. et al. (1982). Antigenic and genetic characterization of a novel hemagglutinin subtype of influenza A viruses from gulls. J. Virol. No 3, 42. P. $865-872$.

7. Hinshaw V.S., Webster R.G., Turner B. (1980). The perpetuation of orthomyxoviruses and paramyxoviruses in Canadian waterfowl. Can. J. Microbiol. No 5. 26. P. $622-629$.

8. Olsen B., Munster V.J., Wallensten A. et al.(2006). Global patterns of influenza a virus in wild birds. Science. V. 312. Is. 5772. P. $384-388$.

9. Spackman. (2014). Animal influenza virus. New York. Humana Press. Second edition.V. 1161. P. $265-$ 276.

10. OIE (2014). Disease Information. Wourld organisation for animal health. $25-1$.

11. Офріційний сайт Державної ветеринарної і фрітосанітарної служби України. www.vet.gov. ua.2014. [In Ukrainian].

12. World Animal Health Information Database (WAHIS) Interface. 2018. http://www.oie.int/wahis_2/public/wahid.php/Wahidhome/Home.

13. Athens G.A. (2008). A laboratory manual for the isolation, identification and characterization of avian pathogens. American Association of Avian Pathologists. 5th ed. 249 p.

14. Swayne D.E. (2012). Impact of vaccines and vaccination on global control of avian influenza. Avian Dis. No 4 Suppl, 56. P. $818-828$.

15. Muzyka D., Pantin-Jackwood M., Spackman E. et al. (2012). Avian influenza virus wild bird surveillance in the Azov and Black Sea regions of Ukraine (2010 - 2011). Avian Dis. No 4 Suppl, 56. P. 1010 - 1016.

16. Muzyka D., Pantin-Jackwood M., Starick E., Fereidouni S. (2016). Evidence for genetic variation of Eurasian avian influenza viruses of subtype H15: the first report of an H15N7 virus. Arch. Virol. No 3, 161. P. $605-612$.

17. Muzyka D., Pantin-Jackwood M.J., Spackman E. et al. (2016). Isolation and genetic characterization of avian influenza viruses isolated from wild birds in the Azov-Black Sea region of Ukraine $(2001-2012)$. Avian Diseases. American Association of Avian Pathologists. 14 - 3 -P. 365 - 377. 